\title{
Correlation between pain and degenerative bony changes on cone-beam computed tomography images of temporomandibular joints
}

\author{
SunMee Bae ${ }^{1}$, Moon-Soo Park', Jin-Woo Han ${ }^{2}$ and Young-Jun Kim ${ }^{1 *}$ (D)
}

\begin{abstract}
Background: The aim of this study was to assess correlation between pain and degenerative bony changes on cone-beam computed tomography (CBCT) images of temporomandibular joints (TMJs).

Methods: Two hundred eighty-three temporomandibular joints with degenerative bony changes were evaluated. Pain intensity (numeric rating scale, NRS) and pain duration in patients with degenerative joint disease (DJD) were also analyzed. We classified condylar bony changes on CBCT into five types: osteophyte (Osp), erosion (Ero), flattening (Fla), subchondral sclerosis (SCl), and pseudocyst (Pse).

Results: Degenerative bony changes were the most frequent in the age groups of 10 19, 20-29, and 50 59 years. The most frequent pain intensity was "none" (NRS 0, 34.6\%) followed by "annoying" (NRS 3-5, 29.7\%). The most frequent condylar bony change was Fla (219 joints, 77.4\%) followed by Ero (169 joints, 59.7\%). "Ero + Fla" was the most common combination of the bony changes (12.7\%). The frequency of erosion was directly proportional to NRS, but the frequency of osteophyte was inversely proportional. The prevalence of Ero increased from onset until 2 years and gradually decreased thereafter. The prevalence of Osp, Ero, and Pse increased with age.
\end{abstract}

Conclusions: Osp and Ero can be pain-related variables in degenerative joint disease (DJD) patients. "Six months to 2 years" may be a meaningful time point from the active, unstable phase to the stabilized late phase of DJD.

Keywords: Temporomandibular joints (TMJ), Cone-beam computed tomography (CBCT), Degenerative bony change, Pain

\section{Background}

Temporomandibular disorder (TMD) refers to a collective term including clinical problems that involve the masticatory muscles, the temporomandibular joint (TMJ), and associated structures [1]. TMD is frequently associated with disc displacement and degenerative changes in the TMJ [2]. Degenerative joint disease (DJD) affects both soft and hard tissues including cartilage, subchondral bone, and synovial membrane. DJD can be diagnosed when there is

\footnotetext{
* Correspondence: alcor3@gwnu.ac.kr

${ }^{1}$ Department of Oral Medicine and Diagnosis, Research Institute of Oral Science, College of Dentistry, Gangneung-Wonju National University, 7 Jukhyun-gil, Gangneung 25457, South Korea

Full list of author information is available at the end of the article
}

either crepitus or radiographic bony changes [3]. Osteoarthrosis is also a DJD in which joint form and structures are abnormal but without signs of arthralgia [3]. DJD causes secondary synovial inflammation, TMJ remodeling, articular cartilage abrasion, and bone degradation characterized by development osteophytes, erosion, flattening, subchondral sclerosis, and pseudocysts $[4,5]$. Detection and evaluation of these bony changes are fundamental for successful diagnosis of DJD [6]. The condition of TMJ can be evaluated by a variety of imaging modalities [7-9]. Cone-beam computed tomography (CBCT) is a fairly new imaging modality that can produce images of high diagnostic quality with a lower radiation dose than medical computed tomography [10-12]. 
It has been controversial whether degenerative bony changes of TMJ can be related to the onset, progression, or regression of TMJ-related signs and symptoms [2, 9]. The aim of this study was to assess the correlation between pain and condylar bony changes on CBCT images in DJD patients.

\section{Methods}

\section{Subjects}

Two hundred and fifty patients who visited the dental hospital from September 2013 to March 2015 complaining of TMJ pains, TMJ sounds, or mouth opening limitation were evaluated. Conventional radiological evaluations (panoramic view and transcranial view) and CBCT examinations were performed. Two hundred one patients (165 women and 36 men) with degenerative bony changes on their conventional radiographies and CBCT images were selected. We excluded normal condyles of DJD patients and finally evaluated 283 condyles.

Pain intensity and pain duration were examined. Pain intensity was evaluated with the numeric rating scale (NRS). We asked patients' average pain intensity of the past 3 days. NRS is 0 to 10 verbal rating scale where "0" was no pain and "10" was the worst pain possible. We classified it into five grades (NRS 0, none; NRS 1-2, mild; NRS 3-5, annoying; NRS 6-7, bad; NRS $8-10$, severe). In addition, we asked patients the onset time of their pain.

\section{Radiographic examination and evaluation}

All subjects were scanned with Alphard-3030 (Asahi Roentgen Co., Kyoto, Japan) with P-mode, operating at $80 \mathrm{kV}, 8 \mathrm{~mA}$ with a voxel of $0.30 \mathrm{~mm}$. The primary reconstruction of the raw data was restricted to the TMJ region (approximately $3.5 \mathrm{~cm}$ superior to the mandibular fossa and $4 \mathrm{~cm}$ inferior, $4 \mathrm{~cm}$ anterior, and $3 \mathrm{~cm}$ posterior to the condylar neck) using Xelis dental program. The long axial view of the examined condyle was traced with the TMJ tool, and the software generated lateral and frontal crosssectional reconstructions perpendicular and parallel to the long axis of the condyle, respectively. The thickness of the image slices was $1 \mathrm{~mm}$, and the distance between slices was $1 \mathrm{~mm}$ for both lateral and frontal reconstructions. The reconstructed images were analyzed by three well-trained dentists. Right and left TMJs were examined separately, resulting in a total of 283 TMJs. Comparing the sagittal, coronal, and 3D images, we classified degenerative bony changes into five types: osteophytes, erosion, flattening, subchondral sclerosis, and pseudocysts [3]. For the accurate assessment, only the bony changes on the articular surfaces were evaluated. Condyles with
Table 1 Distribution of gender

\begin{tabular}{lll}
\hline & Patients & $\begin{array}{l}\text { Degenerative condyles } \\
n(\%)\end{array}$ \\
\hline Women & $165(82)$ & $237(84)$ \\
Men & $36(18)$ & $46(16)$ \\
Total & $201(100)$ & $283(100)$ \\
\hline
\end{tabular}

hyperplasia, deviation in form, and systemic arthritis were excluded in this study. The criteria for the types of condylar bony change shows as follows:

- Osteophytes: marginal bony outgrowths on the condyle

- Erosion: an area of decreased density or discontinuity or irregularity of the cortical bone

- Flattening: a flat bony contour deviating from the convex form

- Sclerosis: an area of increased density of cortical bone extending into the bone marrow

- Pseudocysts: well-circumscribed osteolytic adjacent subcortical bone area without cortical destruction

\section{Statistical analysis}

Simple regression analysis was used to assess the correlation of pain intensity and age on the occurrence of degenerative bone changes. $P$ values less than 0.05 were considered statistically significant. Statistical evaluation of the data was performed using the IBM SPSS Statistics ver. 22.0 for Windows (IBM Co., Armonk, NY, USA)

\section{Results}

This study was performed with 201 patients. The percentage of women (82\%) were higher than men (18\%) (Table 1). Subject age ranged from 12 to 81 years (mean $38 \pm 19$ years) (Table 2). Degenerative bony changes were

Table 2 Distribution of age

\begin{tabular}{lll}
\hline & $\begin{array}{l}\text { Patients } \\
n(\%)\end{array}$ & $\begin{array}{l}\text { Degenerative condyles } \\
n(\%)\end{array}$ \\
\hline $10 \sim 19$ & $51(25.4)$ & $69(24.4)$ \\
$20 \sim 29$ & $40(19.9)$ & $56(19.8)$ \\
$30 \sim 39$ & $16(8.0)$ & $22(7.8)$ \\
$40 \sim 49$ & $27(13.4)$ & $39(13.8)$ \\
$50 \sim 59$ & $39(19.4)$ & $56(19.8)$ \\
$60 \sim 69$ & $17(8.5)$ & $25(8.8)$ \\
$70 \sim 79$ & $9(4.5)$ & $13(4.6)$ \\
$80 \sim 89$ & $2(1.0)$ & $3(1.1)$ \\
Total & $201(100)$ & $283(100)$ \\
\hline
\end{tabular}




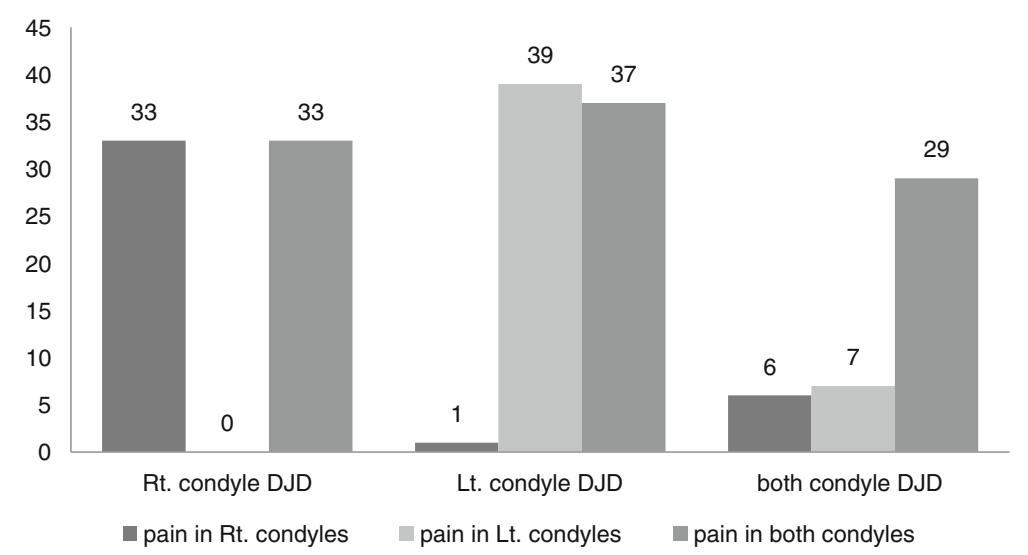

Fig. 1 Prevalence of TMJ pain according to the bony changes. DJD degenerative joint disease, $R t$ right, Lt left, TMJ temporomandibular joint

the most frequent in the age groups of 10 19 years (25.4\%), 20-29 years (19.9\%) and 50 59 years (19.4\%). We could not find an association between age and the prevalence of bony changes.

Figure 1 shows the prevalence of TMJ pain according to the bony changes (left, right, or both). In the case of unilateral DJD, the TMJ pain on the degenerative condyle and the both condyles were similar ("33 vs. 33" and " 39 vs. 37 "). The prevalence of bony changes only in non-painful side was significantly low (0 and 1$)$.

Table 3 presents distribution of degenerative condyles according to pain intensity. The most frequent pain intensity was "none" (NRS 0,34.6\%) followed by "annoying" (NRS 3-5, 29.7\%). Table 4 presents distribution of degenerative condyles according to pain duration. About half of the degenerative condyles were examined at the hospital within 6 months after the pain had occurred.

Accumulative number and percentage of degenerative bony change in degenerative condyles are presented in Table 5. When the multiple radiographic findings were detected in one condyle, each finding was counted separately. The most frequent bony change was "flattening" (219 joints, 77.4\%) followed by "erosion" (169 joints,

Table 3 Distribution of degenerative condyles according to pain intensity

\begin{tabular}{ll}
\hline $\begin{array}{l}\text { Pain intensity } \\
\text { (NRS) }\end{array}$ & $\begin{array}{l}\text { Degenerative } \\
\text { condyles } \\
n(\%)\end{array}$ \\
\hline None $(0)$ & $98(34.6)$ \\
Mild $(1,2)$ & $29(10.2)$ \\
Annoying $(3,4,5)$ & $84(29.7)$ \\
Bad $(6,7)$ & $51(18.0)$ \\
Severe $(8,9,10)$ & $21(7.5)$ \\
Total condyle & $283(100)$ \\
\hline
\end{tabular}

NRS numeric rating scale
59.7\%), and "sclerosis" (139 joints, 49.1\%). Figure 2 shows the distribution of degenerative bony change in degenerative condyles. The combination of erosion and flattening ("erosion + flattening") was the most common bony change (12.7\%). The proportions of degenerative changes detected as combined forms were $77.0 \%$.

Figure 3 presents distribution of types of bone change according to pain intensity. According to the simple regression analysis, pain intensity (categorized into NRS group) showed a statistically significant correlation with "osteophyte" and "erosion" (Table 6). The frequency of erosion was directly proportional to pain intensity, but the frequency of osteophyte was inversely proportional (Fig. 3). Because of insufficient sample size, the NRS 8-10 group was excluded from data analyses. Flattening was the most frequent type (35\%) in none group (NRS 0). Erosion and flattening were the most prevalent changes in all groups except NRS 0 group. The prevalence of erosion increased from onset until 2 years and gradually decreased thereafter (Fig. 4).

Figure 5 shows the distribution of types of bone change according to age. According to the simple regression analysis, age showed a statistically significant correlations with the presence of several bone

Table 4 Distribution of degenerative condyles according to pain duration

\begin{tabular}{ll}
\hline Pain duration & $\begin{array}{l}\text { Degenerative condyles } \\
n(\%)\end{array}$ \\
\hline$\sim 6$ months & $90(48.6)$ \\
6 months 1 year & $16(8.6)$ \\
$1 \sim 3$ years & $28(15.1)$ \\
$3 \sim 10$ years & $40(21.6)$ \\
Over 10 years & $11(5.9)$ \\
& $185(100)$ \\
\hline
\end{tabular}


Table 5 Accumulative number and percentage of degenerative bony change in degenerative condyles

\begin{tabular}{ll}
\hline Bony change & $\begin{array}{l}\text { Degenerative } \\
\text { condyles } \\
n(\%)\end{array}$ \\
\hline Osteophytes & $128(45.2)$ \\
Erosion & $169(59.7)$ \\
Flattening & $219(77.4)$ \\
Sclerosis & $139(49.1)$ \\
Pseudocysts & $43(15.2)$ \\
Total & 698 \\
\hline
\end{tabular}

changes ("osteophyte," "erosion," and "pseudocyst") (Table 7). The prevalence of osteophyte, erosion, and pseudocyst increased with age. Flattening was the most common radiographic finding in all age group. Pseudocyst was observed more in 60-81 years old (12.6\%) than in other age groups.

\section{Discussion}

Several studies reported that the progression and the severity of bony changes on the TMJ increased with age [13-15]. On the other hand, our study revealed that the prevalence of bony changes was higher in the groups of 10 19, 20-29, and 50 59 years old than in other age groups (Table 2). This finding was consistent with the former study [16] that bony changes were more frequent between 20 and 49 years old. Because psychologic status can be a precipitating factor of TMD [17, 18], our finding may be partially related to the stress and the pressure of study for the college entrance examination in Korean

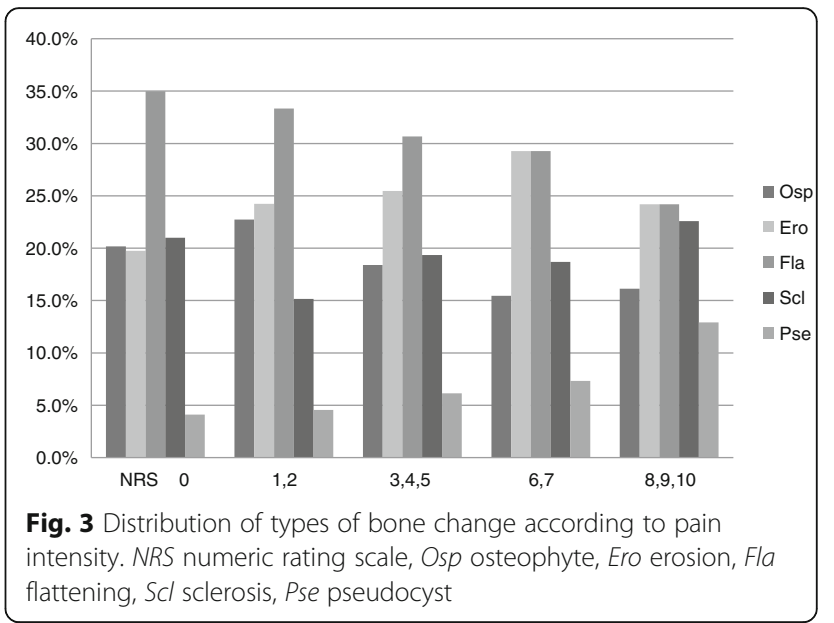

teenagers. In addition, young people have a tendency to visit a hospital more often than aged people (Table 2).

The intermediate phase of bony destruction in TMJ lasts on average 6 months to 1 year [15]. In the present study, $48.6 \%$ of degenerative condyles were examined within 6 months. We speculated that patients usually visited the hospital in their intermediate phase of DJD, when they might undergo spontaneous joint pain, mouth opening limitation, and/or crepitus [5].

Generally, bone deformation characterized in DJD is osteophytes, erosion, flattening, sclerosis, and pseudocysts. Each type of bony change occurs in different stages of DJD and has different clinicopathological meanings [11]. As a condyle has adapted to degenerative changes, tissue remodeling has happened and radiographic

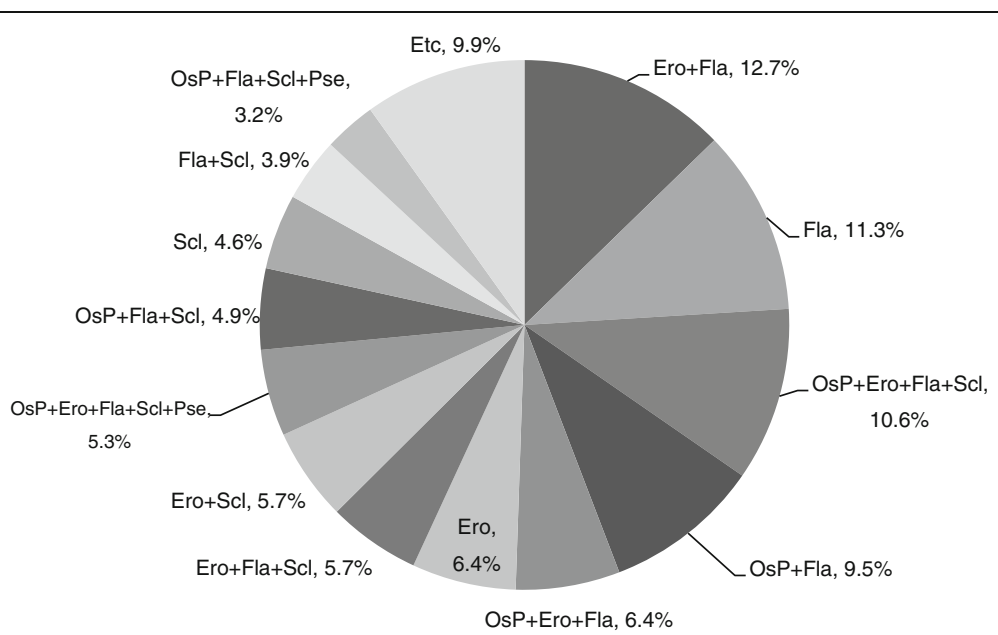

Fig. 2 Distribution of degenerative bony change in degenerative condyles. Osp osteophyte, Ero erosion, Fla flattening, Scl sclerosis, Pse pseudocyst 
Table 6 Result of the simple regression analysis for the presence of degenerative bony changes (osteophyte, erosion) based on pain intensity (categorized into NRS group)

\begin{tabular}{lccccc}
\hline & Coefficient & $\begin{array}{l}\text { Standard } \\
\text { error }\end{array}$ & t score & $p$ value & $\begin{array}{l}95 \% \text { confidence } \\
\text { interval (range) }\end{array}$ \\
\hline Erosion & 1.405 & 0.332 & 4.236 & 0.051 & -0.02 to 2.83 \\
Osteophyte & -0.739 & 0.219 & -3.377 & 0.043 & -1.436 to -0.043 \\
\hline
\end{tabular}

and/or morphologic appearances of condyles have changed accordingly [12]. Several papers reported the distribution of condylar bony changes and their combinations [10, 13, 14]. These studies presented somewhat different results with the others. Dos Anjos Pontual et al. found flattening to be the predominant findings [13]. Wiese et al. found "flattening + osteophyte + erosion" to be the predominant findings [14]. Campos et al. reported that "osteophytes + erosion" was the most frequent combination and osteophyte was the most common single bony change in the MRI study [10]. We found that erosion + flattening was the most frequent (12.5\%), followed by "flattening" (11.5\%), "osteophyte + erosion + flattening + sclerosis" (10.4\%), and "osteophyte + flattening" (10.1\%). The reason for these different results among the studies may be that it was not easy to detect the bony changes definitively, since it is usually a gradual remodeling process $[10,13,14]$. As CBCT has been widely used in assessing TMJ morphology, more specific or detailed guidelines for degenerative bony changes are necessary [19].

Even though pain has occurred only in one side, degenerative condylar changes can be detected on both sides (Fig. 1). One third of degenerative condyles did not show pain (Table 3 ). These results can imply that degenerative changes show some degree of inflammation, producing symptoms that resolve with time, while the previous bony changes still remain [10].

Erosion is a radiographic clue that an active destructive process may be occurring, whereas osteophyte is an indication that the condyle has adapted

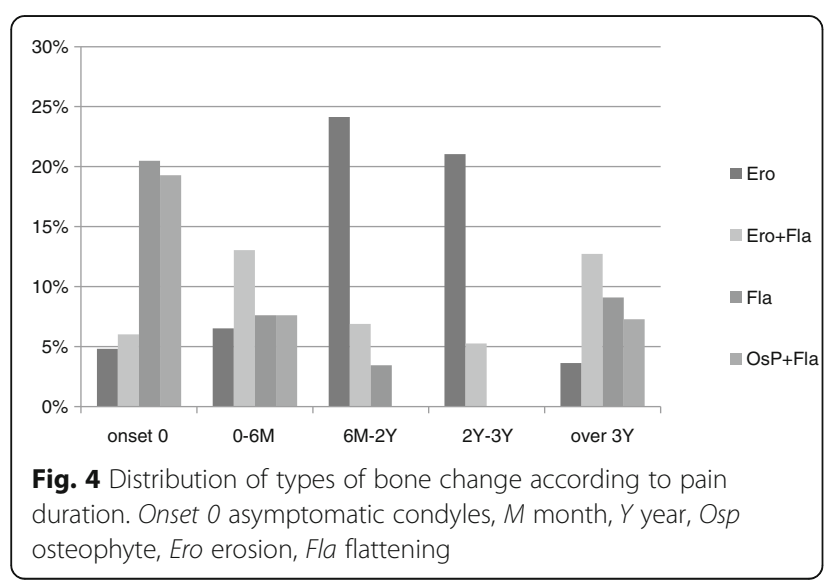

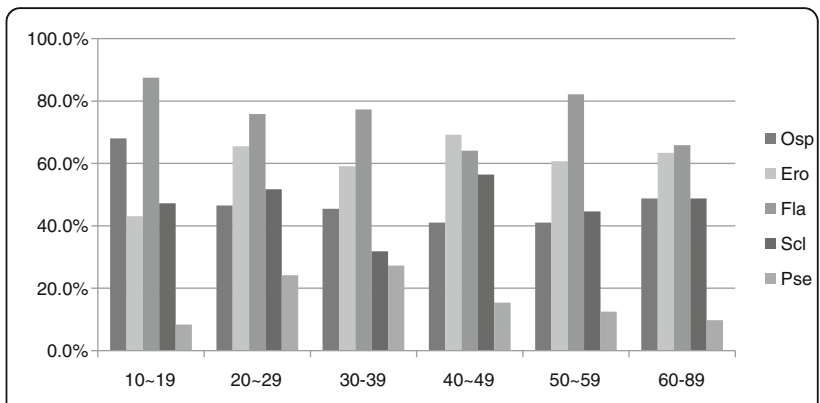

Fig. 5 Distribution of types of bone change according to age. Osp osteophyte, Ero erosion, Fla flattening, Scl sclerosis, Pse pseudocys

to degenerative changes produced in the past [11]. In this study, the frequency of erosion was directly proportional to NRS, but the frequency of osteophyte was inversely proportional (Fig. 3 ). This result demonstrates that the active inflammation of DJD is correlated with the erosion and inversely correlated with the osteophyte.

The prevalence of erosion increased from onset until 2 years and gradually decreased thereafter (Fig. 4). This result suggests "6 months to 2 years" might be a meaningful time point when DJD status changes from the active, unstable phase to the stabilized late phase. The prevalence of osteophyte, erosion, and pseudocyst was increased with age (Fig. 5). Considering these results, we suppose that erosion would have remodeled into osteophyte and/or pseudocyst, as time goes by.

Whereas some previous studies reported that there was poor correlation between bony change and pain [12, 14], our study found that osteophyte and erosion could be pain-related variables in DJD. We speculate that these contradictory results may be due to considering only the existence of bony changes, not the type of bony change in the previous study. There were still controversies about correlation between pain and condylar bony changes $[9,12,14,20]$.

Our study has several limitations such as the limited sample size. Moreover, we evaluated only the first-visit results and excluded the follow-up results. To verify the significant relationships between pain and radiographic findings, further well-organized studies will be needed in the future.

Table 7 Result of the simple regression analysis for the presence of degenerative bony changes (erosion, osteophyte, pseudocyst) based on age groups

\begin{tabular}{lccccc}
\hline & Coefficient & $\begin{array}{l}\text { Standard } \\
\text { error }\end{array}$ & t score & $p$ value & $\begin{array}{l}95 \% \text { confidence } \\
\text { interval (range) }\end{array}$ \\
\hline Erosion & 0.517 & 0.095 & 5.425 & 0.006 & 0.252 to 0.782 \\
Osteophyte & 0.634 & 0.155 & 4.092 & 0.015 & 0.204 to 1.065 \\
Pseudocyst & 0.473 & 0.122 & 3.864 & 0.018 & 0.133 to 0.813 \\
\hline
\end{tabular}




\section{Conclusions}

The present study may find a correlation between pain intensity and degenerative bony changes on CBCT images. Osteophyte and erosion can be pain-related variables in DJD patients. Six months to 2 years may be a meaningful time point from active, unstable phase to stabilized late phase of DJD.

\section{Abbreviations}

CBCT: Cone-beam computed tomography; DJD: Degenerative joint disease; Ero: Erosion; Fla: Flattening; NRS: Numeric rating scale; Osp: Osteophyte Pse: Pseudocyst; Scl: Subchondral sclerosis; TMD: Temporomandibular disorder; TMJ: Temporomandibular joints

\section{Funding}

This study was supported by the Scientific Research (SR 1502) of

Gangneung-Wonju National University Dental hospital.

\section{Authors' contributions}

SMB and JWH are responsible for the data collection. YJK and MSP designed this experiment. SMB wrote the manuscript, and YJK did the critical review on the experimental process. All authors read and approved the final manuscript.

\section{Competing interests}

The authors declare that they have no competing interests.

\section{Consent for publication}

Not applicable.

\section{Ethics approval and consent to participate}

Not applicable.

\section{Publisher's Note}

Springer Nature remains neutral with regard to jurisdictional claims in published maps and institutional affiliations.

\section{Author details}

${ }^{1}$ Department of Oral Medicine and Diagnosis, Research Institute of Oral Science, College of Dentistry, Gangneung-Wonju National University, 7 Jukhyun-gil, Gangneung 25457, South Korea. ²Department of Oral and Maxillofacial Radiology, Research Institute of Oral Science, College of Dentistry, Gangneung-Wonju National University, Gangneung, South Korea.

Received: 19 April 2017 Accepted: 20 May 2017

Published online: 05 July 2017

\section{References}

1. De Leeuw R (2008) Orofacial pain: guidelines for assessment, diagnosis, and management, 4th edn. Quintessence, Chicago, p 131

2. Emshoff R, Puffer P, Rudisch A, Gassner R (2000) Temporomandibular joint pain: relationship to internal derangement type, osteoarthrosis, and synovial fluid mediator level of tumor necrosis factor-alpha. Oral Surg Oral Med Oral Pathol Oral Radiol Endod 90:442-449

3. Dworkin SF, LeResche L (1992) Research diagnostic criteria for temporomandibular disorders: review, criteria, examinations and specifications, critique. J Craniomandib Disord 6(4):301-55

4. Dijkgraaf LC, Liem RS, de Bont LG (1997) Ultrastructural characteristics of the synovial membrane in osteoarthritic temporomandibular joints. J Oral Maxillofac Surg 55:1269-1279

5. Kalladka M, Quek S, Heir G, Eliav E, Mupparapu M, Viswanath A (2014) Temporomandibular joint osteoarthritis: diagnosis and long-term conservative management: a topic review. J Indian Prosthodont Soc 14:6-15

6. Hatcher DC, Aboudara CL (2004) Diagnosis goes digital. Am J Orthod Dentofacial Orthop 125:512-515

7. Brooks SL, Brand JW, Gibbs SJ et al (1997) Imaging of the temporomandibular joint: a position paper of the American academy of oral and maxillofacial radiology. Oral Surg Oral Med Oral Pathol Oral Radiol Endod 83:609-618
8. Koyama J, Nishiyama H, Hayashi T (2007) Follow-up study of condylar bony changes using helical computed tomography in patients with temporomandibular disorder. Dentomaxillofac Radiol 36:472-477

9. Kurita H, Kojima Y, Nakatsuka A, Koike T, Kobayashi H, Kurashina K (2004) Relationship between temporomandibular joint(TMJ)-related pain and morphological changes of the TMJ condyle in patients with temporomandibular disorders. Dentomaxillofac Radiol 33:329-333

10. Campos MI, Campos PS, Cangussu MC, Guimarães RC, Line SR (2008) Analysis of magnetic resonance imaging characteristics and pain in temporomandibular joints with and without degenerative changes of the condyle. J Oral Maxillofac Surg 37:529-534

11. Hussain AM, Packota G, Major PW, Flores-Mir C (2008) Role of different imaging modalities in assessment of temporomandibular joint erosions and osteophytes: a systematic review. Dentomaxillofac Radiol 37:63-71

12. Palconet G, Ludlow JB, Tyndall DA, Lim PF (2012) Correlating cone beam CT results with temporomandibular joint pain of osteoarthritic origin. Dentomaxillofac Radiol 41:126-130

13. Dos Anjos Pontual ML, Freire JSL, Barbosa JMN, Frazao MAG, dos Anjos Pontual A, Fonseca da Silveira MM (2012) Evaluation of bone changes in the temporomandibular joint using cone beam CT. Dentomaxillofac Radiol 41:24-29

14. Wiese M, Svensson P, Bakke M et al (2008) Association between temporomandibular joint symptoms, signs, and clinical diagnosis using the RDC/TMD and radiographic findings in temporomandibular joint tomograms. J Orofac Pain 22:239-251

15. Alexious KE, Stamatakis HC, Tsiklakis K (2009) Evaluation of the severity of temporomandibular joint osteoarthritic changes related to age using cone beam computed tomography. Dentomaxillofac Radiol 38:141-147

16. Cruzoe'-Rebello IMR, Campos PSF, Rubira IRF, Panella J, Mendes CMC (2003) Evaluation of the relation between the horizontal condylar angle and the internal derangement of the TMJ_a magnetic resonance imaging study. Pesqui Odontol Bras 17:176-182

17. Fernandes G, Franco AL, Siqueira JT, Gonçalves DA, Camparis CM (2012) Sleep bruxism increases the risk for painful temporomandibular disorder, depression and non-specific physical symptoms. J Oral Rehabil 39:538-544

18. Van Selms MKA, Lobbezoo F, Wicks DJ, Hamburger HL, Naeije M (2004) Craniomandibular pain, oral parafunctions, and psychological stress in a longitudinal case study. J Oral Rehabil 31(8):738-45

19. Hilgers ML, Scarfe WC, Scheetz JP, Farman AG (2005) Accuracy of linear temporomandibular joint measurements with cone beam computed tomography and digital cephalometric radiography. Am J Orthod Dentofac Orthop 128:803-811

20. Cevidanes LHS, Hajati A-K, Paniagua B, Lim PF, Walker DG, Palconet G et al (2010) Quantification of condylar resorption in temporomandibular joint osteoarthritis. Oral Surg Oral Med Oral Pathol Oral Radiol Endod 110(1):110-7

\section{Submit your manuscript to a SpringerOpen ${ }^{\circ}$ journal and benefit from:}

- Convenient online submission

Rigorous peer review

- Open access: articles freely available online

- High visibility within the field

Retaining the copyright to your article

Submit your next manuscript at $>$ springeropen.com 